

\title{
Matching grants and Ricardian Equivalence
}

\author{
Charles FIGUIERES*and Jean HINDRIKS ${ }^{\dagger}$
}

SEPTEMBER 2001

\begin{abstract}
This paper questions the effectiveness of matching grants to correct for interjurisdictional spillovers in the light of Bernheim general neutrality result. Indeed this result suggests that the usual argument that matching grants are needed to internalize the externality arising from the existence of interjuridictional spillovers is an artifact of the assumption that jurisdictions neglect the impact that their decisions have on the federal budget. Relaxing this assumption and using a classical model where the arbitrage resulting from labor mobility implies that redistribution has the properties of a public good, we find that matching grants are relevant although much less effective. We also find that optimal matching rates are independent of the jurisdictions' choice of policy variable contrarily to the case where jurisdictions ignore the impact of their decisions on the federal budget.
\end{abstract}

JEL Classification: H23, H70 Grants.

Keywords: Fiscal Federalism, Ricardian Equivalence, Matching

\footnotetext{
${ }^{*}$ CORE, 1348 Louvain-la-Neuve, Belgium.

${ }^{\dagger}$ Corresponding author. Department of Economics, Queen Mary, University of London, Mile End Road, London E1 4NS, United Kingdom (phone: + 44207882 7807, fax: +44 208983 3580, j.hindriks@qmul.ac.uk).

${ }^{0}$ The authors would like to thank J. H. Drèze and J. Dutta for helpful comments. This text presents research results of the Belgian Program on Interuniversity Poles of Attraction initiated by the Belgian State, Prime Minister's Office, Science Policy Programming. The scientific responsibility is assumed by the authors.
} 


\section{Introduction}

Redistributive programmes are the largest component of public expenditures in most industrialised countries. ${ }^{1}$ With the ongoing process of integration and the simultaneous devolution of tax and spending responsibilities to lower level governments, many countries have become concerned about the sustainability of redistributive programmes. Increasing labour mobility makes redistribution more difficult as each state seeks to limit immigration of the poor and out-migration of the rich by setting low level of redistribution and taxation. ${ }^{2}$

The present paper stands at the intersection of two lines of research. In the fiscal federalism literature (as in [12]) and textbook treatment (as in [10]) one argument for intergovernmental transfers is to internalise the externality arising from the existence of interjurisdictional spillovers either through public good provision or labour mobility. To restore the Paretooptimal outcome, a system of matching grants from the federal government to lower level of governments is needed. It means that local states determine their expenditure levels and the federal government pays a fraction of the costs. $^{3}$

However a different strand of literature on Ricardian equivalence as exemplified by [3] is very pessimistic about the capacity of a central government to correct that kind of externalities and in particular to restore the optimal provision of public good through tax-subsidy policies. ${ }^{4}$ One critical assumption is whether agents take the central government tax-subsidy policy as parametric or not when optimising. Tax-subsidy are effective when agents select their policy to maximise their welfare, taking as given the pol-

\footnotetext{
${ }^{1}$ For the European Community in 1998 the average GDP share of all transfer spending to individuals was 21.6 percent (see [2]).

${ }^{2}$ An excellent survey of the empirical studies of welfare migration is provided in [6]. See also [14] for a presentation of the redistribution and mobility issues in the European context.

${ }^{3}$ Evidence on the importance of intergovernmental transfers in some federal countries are provided in [7]. In the US, the federal government could bear 50-80 percent of the cost of the AFDC (Aid to Families with Dependent Children) expenditures undertaken by states. In 1996, the AFDC was replaced by a block grant programme (i.e., TANF), but the food stamp programme and the Medicaid programme continued under a matching system.

${ }^{4}$ The word Ricardian Equivalence was coined by [1], who argued that debt and finance are equivalent because intergenerational transfers could be offset by private voluntary transfers. This argument was indeed already presented by Ricardo who also expressed scepticism about its empirical relevance.
} 
icy of the central government. This implies that they ignore the requirement that the budget of the central government be balanced. The presumption is that there are enough agents for each to ignore the effects of their policy on the government budget. With many agents, like individual taxpayers, this is a reasonable assumption. However when there are few agents, like regional jurisdictions in a federal system, then it is less legitimate to assume that each has a negligible impact on government revenue. Then a simple inference from Bernheim's equivalence result suggests that tax-subsidy policy becomes ineffective. This result has been established formally by [4] in a fiscal federalism context of public good provision without mobility. They showed that matching grants are ineffective when jurisdictions see through the federal budget and take into account the impact of their decision on it.

In this paper we use the classic model of [12] to question the effect of the so-called see through assumption on the effectiveness of matching grant in the context of redistribution with mobility. Regional social welfare functions reflects some (unexplained) motive for redistribution. Redistribution is similar to a public good since when labour is mobile, by arbitrage all states will end up with the same equilibrium "welfare of the poor". A distinguishing feature of this framework is that redistribution interacts directly with the working of the labour market as it affects the allocation of factors across states, the economic rent and the amount of output available.

A first result is that in this model of redistribution as a public good, matching grants are not irrelevant even with see-through, although they are much less effective. The reason why matching grants are not neutral is that acting to offset the federal policy change is distortionary. Offsetting changes in the states' redistributive policies distort the allocation of labour and affects the labour supply of each state. By contrast in [3] labour supply precedes contributions to the public goods (or in [4] is simultaneous) so that offsetting changes in contributions are not distortionary at all. To put it differently, redistribution with mobility has also an impact on the labour market which creates a second spillover between states through its effects on labour allocation which is not present in Bernheim's neutrality result.

Another finding is that with see-through optimal matching grants are independent of the states'choice of policy variable. This is a rather unexpected result since it is well known from the tax competition literature (see e.g. [8]), that different decision variables lead to different outcomes. ${ }^{5}$ Indeed we show that when states ignore the impact of their decision on the federal

\footnotetext{
${ }^{5}$ This is analogue to the usual distinction in industrial organisation between Cournot and Bertrand competition.
} 
budget (taking the federal policy as given) then tax competition requires higher matching grants than benefit (expenditure) competition to restore the first-best outcome. So it turns out that with see through this sensitivity of the optimal matching grant completely disappears.

We develop our analysis in a set up where states are assumed to be identical, and only symmetric Nash equilibria (among the states) are considered. This of course, rules out one of the key role of intergovernmental transfers which is to correct for differences in fiscal capacities or needs across states. Our purpose in adopting this simplication is to ensure that matching grants result solely from the need to internalise the externality arising from the existence of interjurisdictional spillovers (i.e efficiency role of matching grants).We also abstract from the risk sharing role of matching grants as in [9] by assuming away uncertainty.

The rest of the paper proceeds as follows. In section 2 we describe the basic framework. In section 3, we derive the Pareto optimal outcome as a benchmark for the rest of the analysis. In section 4 we analyse the effect of the see-through assumption on the optimal matching grants when states compete in benefit levels. In section 5, it is assumed instead that states compete in taxes. The concluding section summarises the results and discusses possible implications.

\section{The framework}

The presentation of the model will be brief. ${ }^{6}$ A federation is composed of $k$ states indexed by $i$. In each state there is one representative rich resident who is immobile; there are also $l_{i}$ poor that are mobile. The total number of poor in the economy is fixed, i.e.

$$
\sum_{i} l_{i}=k l .
$$

States produce a private consumption good with a ricardian technology $f\left(l_{i}\right)$, which is increasing and concave $\left(f^{\prime}\left(l_{i}\right)>0\right.$ and $\left.f^{\prime \prime}\left(l_{i}\right)<0\right)$. Workers are paid at their marginal productivity: wages in state $i$ are $w\left(l_{i}\right)=f^{\prime}\left(l_{i}\right)$. Note that wages in state $i$ decrease with the number of poor in that state: $w^{\prime}\left(l_{i}\right)=f^{\prime \prime}\left(l_{i}\right)<0$.

The per capita transfer that accrues to the poor in state $i$ is denoted $z_{i}$. The total income of a poor in state $i$ is thus $w\left(l_{i}\right)+z_{i}$. Since poor can

${ }^{6}$ More details can be found in [11] or [12]. 
migrate costlessly from one state to another, necessarily:

$$
c=w\left(l_{i}\right)+z_{i}=w\left(l_{j}\right)+z_{j}, \quad \forall j \neq i
$$

The rich resident captures the return to the fixed factors of production. So the (gross) income of the rich in state $i$ is

$$
y\left(l_{i}\right)=f\left(l_{i}\right)-f^{\prime}\left(l_{i}\right) l_{i} .
$$

This income is used to consume private good $x_{i}$ and to pay the tax $\tau_{i}$ so that $x_{i}=y\left(l_{i}\right)-\tau_{i}$.

All states exhibit identical social welfare function $W$ defined over the consumption $x_{i}$ of their rich resident and the income $c$ of their poor residents, reflecting some (unexplained) motives for redistribution. The function $W\left(x_{i}, c\right)$ is assumed to be quasiconcave and its (positive) partial derivatives are denoted $W_{1}$ and $W_{2}$.

Fiscal revenue in each state $\tau_{i}$ serves to finance the welfare benefits to its poor residents $(1-s) l_{i} z_{i}$, (net of the federal subsidies $s l_{i} z_{i}$ ) plus the federal tax $T$. Given our symmetric framework it is assumed that states are all facing the same matching rate $s \in[0,1[$ and pay the same federal contribution $T$. Hence, the state budget constraints are:

$$
\tau_{i}=(1-s) l_{i} z_{i}+T, \quad i=1, \ldots, k
$$

and the federal budget constraint is:

$$
\sum_{i=1}^{k} s l_{i} z_{i}=k T
$$

\section{Conditions for Pareto optimality}

In this model any Pareto optimal allocation of labour has to maximise the total output $\sum f\left(l_{i}\right)$ which given identical technologies across states requires workers to be evenly distributed ( i.e. $l_{i}=l$, so that $f^{\prime}\left(l_{i}\right)=f^{\prime}(l)$ for all $i$ ). Using this productive efficiency condition, Pareto optimal allocation must also involve a level of income of the poor $c$ that solves

$$
\max _{c \geq 0} \sum_{i=1}^{k} W\left(f_{i}(l)-l c, c\right)
$$


The necessary and sufficient first-order condition for the (interior) optimal level of $c$ is then

$$
\sum_{i=1}^{k} \frac{W_{2}}{W_{1}}=k l
$$

This is the familiar Samuelson condition for the efficient provision of public good. Given the public good property of the income of the poor, $c$, at an interior solution we must have that the sum of the marginal benefits from raising the income of the poor is equal to its marginal cost.

\section{Mobility externality and matching grants}

\subsection{No see through}

In [12] it is assumed that states take the federal policy $(T, s)$ as given and choose simultaneoulsy and non-cooperatively the benefit levels $z_{i}$ to their poor residents with the tax rates $\tau_{i}$ being residually determined by the resulting migrations to balance their budget (i.e., benefit competition). Formally, each state $i$ takes the benefit levels of other states $z_{j}(j \neq i)$ and the federal policy $(T, s)$ as given and solves

$$
\max _{z_{i}} W\left(y\left(l_{i}\right)-\tau_{i}, c\right)
$$

subject to conditions (1),(2), (3) and (4).

We derive the symmetric Nash equilibrium in which $(i)$ no poor wants to migrate, $(i i)$ no state wants to change its policy choice given the policy choices of other states and the federal policy, (iii) the budget of every state is balanced, and $(i v)$ the federal budget is balanced. ${ }^{7}$ The first-order condition for state $i$ is

$$
W_{1}\left[y^{\prime}\left(l_{i}\right) \frac{d l_{i}}{d z_{i}}-\frac{d \tau_{i}}{d z_{i}}\right]+W_{2} \frac{d c}{d z_{i}}=0
$$

where from (3), $y^{\prime}\left(l_{i}\right)=-l_{i} f^{\prime \prime}\left(l_{i}\right)$. The migration effect of a change in $z_{i}$ holding constant $z_{j}$ (for all $j \neq i$ ) is obtained by totally differentiating (1) and (2) with respect to $z_{i}, l_{i}, l_{j}$ which evaluated at a symmetric equilibrium gives $^{8}$

\footnotetext{
${ }^{7}$ In symmetric equilibrium, mobility does not affect the allocation of population among states, that is not to say, however, that it is irrelevant to the states' choice of redistributive policies!

${ }^{8}$ All the (implicit) differentiations are without surprise and the details are omitted to save space.
} 


$$
\begin{gathered}
\frac{d l_{i}}{d z_{i}}=-\frac{k-1}{k w^{\prime}}>0 \\
\frac{d l_{j}}{d z_{i}}=\frac{1}{k w^{\prime}}<0 \quad \forall j \neq i
\end{gathered}
$$

Differentiating both (2) and (4) with respect to $z_{i}$, using (8) and symmetry, we obtain respectively

$$
\frac{d c}{d z_{i}}=\frac{1}{k}
$$

and

$$
\frac{d \tau_{i}}{d z_{i}}=(1-s)\left(l-\frac{k-1}{k} \frac{z}{k w^{\prime}}\right)
$$

Plugging (8), (10) and (11) into (7) and rearranging, the first-order condition becomes,

$$
\frac{W_{2}}{W_{1}}=(1-s k) l-(1-s)(k-1) \frac{z}{w^{\prime}}
$$

Comparing this condition with (6), it is readily seen that it is possible to implement the first best solution as a Nash equilibrium by setting the matching rate $s$ such that the right hand side of this condition equates $l$. This requires the following optimal matching rate,

$$
s^{\circ}=\frac{1}{1-\frac{k}{k-1} \frac{w}{z \varepsilon}} \in(0,1)
$$

where $\varepsilon \equiv d \log l / d \log w=w / w^{\prime} l<0$ is the labor-demand elasticity evaluated at the symmetric equilibrium. This is the classical matching grant as derived in [12] for identical states (see Proposition 4). This result is obtained by assuming that states take the federal policy as given and so behave as if their policy choice had no influence on the federal budget.

Now we relax this assumption and assume as in [3] that states can see through the federal budget and take into account the effect of their policy choices on the federal tax $T$. Our purpose is to see how this see-through assumption affects the effectiveness of matching grant and, in particular, whether the general neutrality result of Bernheim applies in this model. 


\subsection{See through}

Substituting the federal budget constraint (5) for $T$ into every state $i$ 's budget constraint (4),

$$
\tau_{i}=\left(1-\frac{k-1}{k} s\right) l_{i} z_{i}+\frac{s}{k} \sum_{j \neq i} l_{j} z_{j}
$$

State i's problem is the same as before except that the condition (4) is replaced by (13).

The general expression for the first-order condition for state $i$ is still given by (7) where $d l_{i} / d z_{i}$ and $d c / d z_{i}$ are unchanged (resp., (8) and (10)) but from (13) $d \tau_{i} / d z_{i}$ evaluated at a symmetric equilibrium becomes

$$
\begin{aligned}
\frac{d \tau_{i}}{d z_{i}} & =\left(1-\frac{k-1}{k} s\right)\left(l+z \frac{d l_{i}}{d z_{i}}\right)+\frac{s}{k} \sum_{j \neq i} z \frac{d l_{j}}{d z_{i}} \\
& =\left(1-\frac{k-1}{k} s\right)\left(l-\frac{k-1}{k} \frac{z}{w^{\prime}}\right)+\frac{k-1}{k} s \frac{z}{k w^{\prime}}
\end{aligned}
$$

where the second equality follows from (8) and (9). Using (8), (10) and (14), the first-order condition becomes after some manipulation

$$
\frac{W_{2}}{W_{1}}=\left(1-\frac{k-1}{k} s\right) k l-(1-s)(k-1) \frac{z}{w^{\prime}}-(k-1) l
$$

Since first best requires the right-hand side of this expression to be equal to $l$, the optimal matching grant is

$$
\widetilde{s}^{\circ}=\frac{1}{1-\frac{w}{z \varepsilon}} \in(0,1)
$$

where $\varepsilon=w / w^{\prime} l<0$ is used. Three conclusions emerge immediately. Firstly matching grants can restore the first-best even if agents see through the federal budget, so the neutrality result of Berheim does not apply. Secondly a higher matching rate is required to correct the fiscal externality under the see-through assumption (i.e., $\widetilde{s}^{\circ}>s^{\circ}$ ). Thirdly, with see-through, the number of states is irrelevant to the choice of the optimal matching rate. To summarize.

Proposition 1: For any (symmetric) Nash equilibrium of the benefit competition game between $k \geq 1$ states, matching grants can achieve the 
first-best regardless of the see-through assumption. It only takes a higher matching grant with see-through. Moreover the effect of see-through is to make the optimal matching rate independent of the number of competing states.

In the next section we relax the assumption we have made so far that states compete through benefit levels and instead assume that the policy variable is the tax while the benefit levels are determined residually according to migration to maintain budget balance. Again our purpose is to show how the see through assumption affects the optimal matching rate and whether there is a possibility of neutrality.

\section{Tax competition}

\subsection{No see through}

State $i$ selects a tax $\tau_{i}$ taking the tax rates of other states $\tau_{j}(j \neq i)$ and the federal policy $(T, s)$ as given so as to solve

$$
\max _{\tau_{i}} W\left(y\left(l_{i}\right)-\tau_{i}, c\right)
$$

subject to conditions (1),(2), (3) and

$$
z_{i}=\frac{\tau_{i}-T}{(1-s) l_{i}} \quad \text { for all } i
$$

The corresponding first-order condition is:

$$
W_{1}\left[y^{\prime}\left(l_{i}\right) \frac{d l_{i}}{d \tau_{i}}-1\right]+W_{2} \frac{d c}{d \tau_{i}}=0
$$

The migration effect of a change in $\tau_{i}$ holding constant $T, s$, and $\tau_{j}$ (with $j \neq i$ ) is obtained by totally differentiating (1) and (2) with respect to $\tau_{i}, l_{i}, l_{j}$ using (15), which when evaluated at a symmetric equilibrium gives

$$
\begin{gathered}
\frac{d l_{i}}{d \tau_{i}}=\frac{k-1}{k(1-s)\left(z-w^{\prime} l\right)}>0 \\
\frac{d l_{j}}{d \tau_{i}}=-\frac{1}{k(1-s)\left(z-w^{\prime} l\right)}<0 \quad \forall j \neq i
\end{gathered}
$$


So, matching grants amplify the migration response to tax change. Differentiating (2) with respect to $\tau_{i}$, using (15),(17), and symmetry, we obtain

$$
\frac{d c}{d \tau_{i}}=\frac{1}{(1-s) k l}
$$

Plugging (17), (19) into (16) and using the fact that $y^{\prime}=-l f^{\prime \prime}=-l w^{\prime}$ in a symmetric equilibrium, we get

$$
\frac{W_{2}}{W_{1}}=\left[(1-s)+w^{\prime} l \frac{k-1}{k\left(z-w^{\prime} l\right)}\right] k l
$$

Comparing this condition with (6), restoring the first best solution requires to set the matching rate such that the right hand side of this condition is equal to $l$. This leads to the following optimal matching rate,

$$
s^{*}=\frac{1}{\frac{k}{k-1}\left(1-\frac{w}{z \varepsilon}\right)} \in(0,1)
$$

Note that $s^{*}<s^{\circ}$ which means that tax competition requires a lower matching grant to restore efficiency than benefit competition. The reason is that competition in taxes is less severe because increasing tax in one state holding the tax rates in other states constant, attracts some of the poor in that state enabling the other states to raise their benefit levels. So more redistribution in one state triggers more redistribution in other states; while under benefit competition more redistribution in one state triggers less taxation in other states (see [8] and [13] for similar result). It is worth noting that as $k \rightarrow+\infty$ the two games require the same matching rate. In fact, from (10) and (19), $d c / d z_{i}=d c / d \tau_{i} \rightarrow 0$ as $k \rightarrow+\infty$ so that tax change has the same negligible effect on the income of the poor as benefit change when the number of states is very large. ${ }^{9}$ We thus have,

Proposition 2: With non-see-through, the matching grants required to attain the first-best depend on the the states' choice of policy variable. Competition in taxes requires lower matching grants than competition in benefit levels. In both cases optimal matching grants are increasing with the number of competing states and converge to the same level $\widetilde{s}^{\circ}=\frac{1}{1-\frac{w}{z \varepsilon}}$ as $k \rightarrow \infty$.

We now allow for see-through in this tax competition game.

\footnotetext{
${ }^{9}$ See also [13] for a similar result in the context of capital mobility.
} 


\subsection{See through}

Substituting (5) for $T$ into (4),

$$
\tau_{i}=(1-s) l_{i} z_{i}+\frac{s}{k} \sum_{j=1}^{k} l_{j} z_{j} \quad \text { for all } i
$$

Summing these $k$ identities

$$
\begin{aligned}
\sum_{j=1}^{k} \tau_{j} & =(1-s) \sum_{j=1}^{k} l_{j} z_{j}+s \sum_{j=1}^{k} l_{j} z_{j} \\
& =\sum_{j=1}^{k} l_{j} z_{j}
\end{aligned}
$$

Combining these two expressions

$$
\tau_{i}=(1-s) l_{i} z_{i}+\frac{s}{k} \sum_{j=1}^{k} \tau_{j} \text { for all } i
$$

Solving this expression for $z_{i}$ one finds:

$$
z_{i}=\frac{\left(1-\frac{s}{k}\right) \tau_{i}-\frac{s}{k} \sum_{j \neq i} \tau_{j}}{(1-s) l_{i}} \text { for all } i
$$

State's problem is the same as without see through asumption except that the condition (15) is replaced by (21).

Totally differentiating (1) and (2) with respect to $\tau_{i}, l_{i}, l_{j}$ using (21), and evaluating at a symmetric equilibrium gives

$$
\begin{gathered}
\frac{d l_{i}}{d \tau_{i}}=\frac{k-1}{k(1-s)\left(z-w^{\prime} l\right)}>0 \\
\frac{d l_{j}}{d \tau_{i}}=-\frac{1}{k(1-s)\left(z-w^{\prime} l\right)}<0 \quad \forall j \neq i
\end{gathered}
$$

Note that under tax competition, the migration effects of a tax change are the same with or without the see-through assumption (see (17) and (18)). Differentiating (2) with respect to $\tau_{i}$, using (21),(22), and symmetry, we obtain 


$$
\begin{aligned}
\frac{d c}{d \tau_{i}} & =\frac{\partial z_{i}}{\partial \tau_{i}}+\left(w^{\prime}-\frac{z}{l}\right) \frac{d l_{i}}{d \tau_{i}} \\
& =\frac{1-s / k}{(1-s) l}-\frac{1-1 / k}{(1-s) l} \\
& =\frac{1}{k l}
\end{aligned}
$$

Note again that $d c / d \tau_{i} \rightarrow 0$ as the number of jurisdictions increases to infinity. Reporting (22) and (24) into the first order condition (16), using the fact that $y^{\prime}(l)=-l w^{\prime}$ and rearranging one obtains:

$$
\frac{W_{2}}{W_{1}}=\left[1+w^{\prime} l \frac{k-1}{k(1-s)\left(z-w^{\prime} l\right)}\right] k l
$$

Restoring the first-best requires to choose $s$ such that the right-hand side of this expression equates $l$. This yields the following matching grant.

$$
\widetilde{s}^{*}=\widetilde{s}^{\circ}=\frac{1}{1-\frac{w}{z \varepsilon}}
$$

So with see-through, the optimal matching grant is the same whether states compete in taxes or in benefits. This was true with non-see-through only in the limiting case of an infinite number of states. Note that the optimal matching rate is also independent of the number of states. Lastly simple comparison of the matching rates reveals that $\widetilde{s}^{*}=\frac{k}{k-1} s^{*}$ so that optimal matching rates under see-through may be up to twice the matching rate without see through. Therefore we have

Proposition 3: With see-through the optimal matching grant is the same whether states compete in taxes or in benefit levels and is independent of the number of states. This matching grant may be up to twice the matching grant without see through.

The key to the different results in the Bernheim and our model, as outlined in the introduction, is that in the Bernheim model contributions are chosen after labour supply and thus are not distortionary at all; whereas in our model contributions are chosen before labour supply is determined through the resulting migration. To understand the critical role of this distortion, suppose that states do not care about productive efficiency. It 
follows that states do not take into account the distortionary effect of their policy choices on the allocation of labour. This can be easily captured in our model by assuming that $y^{\prime}=0$. Plugging this value into the first-order condition (16) and using (22) and (24) give:

$$
\frac{W_{2}}{W_{1}}=k l
$$

So, the first-order condition would be now independent of the matching rate $s$ and the neutrality result would follow.

\section{Conclusion}

This paper has analysed the effectiveness of matching grants to correct for interjurisdictional spillovers due to mobility. We have used a classical model of welfare competition in which states seek to redistribute income but face a mobility constraint. The model shares the properties of private contribution to public good models since with mobility, by arbitrage all states end up with the same level of income for the poor. It follows that redistribution of income in each state is akin to the voluntary contribution of a public good (namely, the income of the poor). The Nash equilibrium involves too few redistribution and a subsidy policy like matching grants can be used to restore the Pareto optimal outcome. However, unlike the previous papers having investigated this issue, we have allowed for the (reasonable) possibility that states take into account the impact of their decisions on the federal budget (i.e., see through assumption). Because states fully take into account the taxes they will have to pay as a result of the subsidies they receive, and because all states are linked through their voluntary contributions to public good, it is natural to wonder whether Berhneim general neutrality result, based on these two assumptions, would apply. Our analysis reveals that the answer is no. Matching grants are not neutral in our model although the seethrough assumption make them much less effective. So we do not have that federal policy change triggers offsetting changes from states. The reason is that, with mobility, offsetting change in states' contributions to public good is distortionary as it affects the allocation of labour. In contrast, Berhneim neutrality relies on the assumption that voluntary contributions are not distortionary because labour supply is determined before contributions. To put it differently, mobility invalidates the key assumption in Berhneim theorem that: agents (states) care about the magnitude of their contributions only 
insofar as these contributions affect the aggregate level of public good. In our model contributions also affect the allocation of labour and economic rent in each state.

Our analysis has also revealed some other interesting results. In particular, we have shown that, contrary to conventional results, the states' choice of policy variable (i.e., competing in taxes or competing in benefits) and the number of competing jurisdiction are irrelevant for the calculation of optimal matching grants. Previous work rather suggests that competition increases with the number of jurisdictions and that benefit competition is more severe than tax competition, and so that higher matching grants are needed. The key to the different results is that we allow for states to take into account the impact of their decision on the federal budget which is a sensible assumption when there are only few states. Not too surprisingly, we have also found that this see-through assumption is becoming decreasingly relevant as the number of states increases.

Attention has been restricted in our analysis to identical jurisdictions and symmetric Nash equilibrium to ensure that any matching grants emerge solely from efficiency grounds. We have thus abstracted from the heterogeneity neutralising and risk sharing effect of matching grants. For the distortion reason already outlined we can expect the non neutrality result of matching grants to carry over in a more general model of heterogenous states provided there is mobility of factors. We have also abstracted from the possibility of using block grants instead of matching grants. This is a contentious issue that may be worth investigating in future research.

\section{References}

[1] Barro, R.J., 1974, Are government bonds net wealth?, Journal of Political Economy 82, 1195-1197.

[2] Bean, C., S. Bentolila, G. Bertola and J. Dolado, 1998, Social Europe:One for all? London:CEPR.

[3] Bernheim, B.D., 1986, On the voluntary and involuntary provision of public goods, American Economic Review 76, 789-93.

[4] Boadway, R., P. Pestieau, and D. Wildasin, 1989, Tax-transfer policies and the voluntary provision of public goods, Journal of Public Economics 39, 157-76. 
[5] Brown, C. and W. Oates, 1987, Assistance to the poor in a federal system, Journal of Public Economics 32(3), 307-330.

[6] Brueckner, J.K., 2000, Welfare Reform and the Race to the Bottom: Theory and Evidence, Southern Economic Journal 66(3), 505-525.

[7] Costello, D., 1993, Intergovernmental grants: what role for the European Community?, European Economy, no 5.

[8] Hindriks, J., 1999, The consequences of labour mobility for redistribution:tax versus transfer competition, Journal of Public Economics 74, $215-34$.

[9] Lockwood, B., 1999, Inter-regional insurance, Journal of Public Economics $72,1-37$

[10] Oates, W.E., 1972, Fiscal federalism, Harcourt Brace Jovanovich: New York.

[11] Pfingsten A. and A. Wagener, 1997, Centralized vs. Decentralized Redistribution: A case for Interregional Transfer Mechanisms, International Tax and Public Finance 4, 429-451.

[12] Wildasin, D.E., 1991, Income redistribution in a common labor market, American Economic Review 81, 757-74.

[13] Wildasin, D.E., 1988, Nash equilibria in models of fiscal competition, Journal of Public Economics 35, 229-240.

[14] Wildasin, D.E., 2000, Factor mobility and fiscal policy in the EU: policy issues and analytical approaches, Economic Policy, October, 339-78. 


\section{Q Queen Mary \\ University of London}

This working paper has been produced by the Department of Economics at Queen Mary, University of London

Copyright $\odot 2001$ Charles Figuieres and Jean Hindriks All rights reserved.

\section{Department of Economics}

Queen Mary, University of London

Mile End Road

London E1 4NS

Tel: +44 (0)20 78825096 or Fax: +44 (0)20 89833580

Email: j.conner@qmw.ac.uk

Website: www.econ.qmw.ac.uk/papers/wp.htm 